\title{
Multiorgan failure and rhabdomyolysis in a recent émigré: Your diagnosis?
}

\author{
Mona Rafik Loutfy MD FRCPC ${ }^{1}$, Jordan Jay Feld MD² ${ }^{2}$ John Maynard Conly MD FRCPC ${ }^{1}$
}

A 21-year-old East Indian man, who had arrived to Canada one month earlier, was brought to the emergency room because of fever and rigors. He had been well until nine days previous, when he first noted fever, nausea, vomiting, oral ulcerations and odynophagia. Over the next few days, his fever persisted and he noted darkening of his urine and thigh pain on walking. During the two days before admission, his symptoms intensified, and he became confused and lethargic. The patient had had no previous health problems, was not on any medications and had no allergies. There was no history of alcohol, tobacco or illicit drug use. He denied any recent contact with animals or anyone with a febrile illness. Having arrived from India only one month earlier, the patient was unemployed.

Physical examination revealed a well developed but disheveled ill looking young man. The pulse was 110 beats/min, blood pressure was $140 / 100 \mathrm{mmHg}$, respiratory rate was 20 breaths $/ \mathrm{min}$ and the temperature was $37.9^{\circ} \mathrm{C}$ orally. The mucous membranes were extremely dry, and there were ulcerations of the buccal mucosa. There were no abnormalities on cardiac or respiratory examination. There was no abdominal tenderness and no masses or organomegaly. Bowel sounds were normal, and the stool was positive for occult blood. He was oriented to person and time only. There was no meningismus. He was somnolent but rousable, and there were no focal neurological signs.
Complete blood count revealed a hemoglobin of $116 \mathrm{~g} / \mathrm{L}$, a leukocyte count of $2000 / \mu \mathrm{L}$ and a platelet count of $32,000 / \mu \mathrm{L}$. Serum electrolytes were as follows: sodium $142 \mathrm{mmol} / \mathrm{L}$, potassium $6.1 \mathrm{mmol} / \mathrm{L}$, chloride $106 \mathrm{mmol} / \mathrm{L}$, and bicarbonate 19 $\mathrm{mmol} / \mathrm{L}$. Other serum values were as follows: blood urea 55 $\mathrm{mmol} / \mathrm{L}$, creatinine $1101 \mu \mathrm{mol} / \mathrm{L}$, aspartate aminotranferase $3028 \mathrm{U} / \mathrm{L}$, alanine aminotranferase $481 \mathrm{U} / \mathrm{L}$, alkaline phosphatase (ALP) $92 \mathrm{U} / \mathrm{L}$, bilirubin $13 \mu \mathrm{mol} / \mathrm{L}$, lactic dehydrogenase (LDH) $7100 \mathrm{U} / \mathrm{L}$, amylase $177 \mathrm{U} / \mathrm{L}$, calcium $1.7 \mathrm{mmol} / \mathrm{L}$, phosphate $2.2 \mathrm{mmol} / \mathrm{L}$, albumin $34 \mathrm{~g} / \mathrm{L}$, and creatine phosphokinase (CPK) 102, $500 \mathrm{U} / \mathrm{L}$. The coagulation studies revealed an international normalized ratio of 1.39 and a partial thromboplastin time of $43.8 \mathrm{~s}$. A urinalysis showed $3+$ blood and $3+$ protein. The sediment contained few erythrocytes and many granular casts.

In summary, this patient presented with fever, pancytopenia, hepatitis, coagulopathy, rhabdomyolysis and acute renal failure. He was started on hemodialysis and received a five unit platelet transfusion. The patient subsequently passed a large quantity of bright red blood per rectum, with a fall in his hemoglobin. A bleeding scan revealed intermittent bleeding localized to the caecum.

What is the diagnosis?

Continued on next page

\footnotetext{
${ }^{1}$ Division of Infectious Diseases, Department of Medicine, University of Toronto; ${ }^{2}$ Department of Medicine, University of Toronto, Toronto, Ontario

Correspondence and reprints: Dr John Maynard Conly, Toronto General Hospital, University Health Network, 200 Elizabeth Street, 13 Norman Urquart Wing, Suite 117, Toronto, Ontario M5G 2C4. Telephone: 416-340-4858, fax 416-340-5047, e-mail john.conly@uhn.on.ca
} 
Continued from previous page

\section{DIAGNOSIS}

Blood cultures from admission grew Salmonella typhi, sensitive to ampicillin and ciprofloxacin (Cipro, Bayer Healthcare Division, Toronto, Ontario). Thick and thin smears for malaria were negative. Stool and urine cultures were negative. Serology for leptospirosis, rickettsia, dengue and trichenella were negative. A throat viral culture and monospot were negative. The patient was treated with ciprofloxacin for 14 days. CPK and creatinine levels fell to normal. His hematological parameters normalized, and he stopped bleeding. He had no further complications and was discharged four weeks after admission with normal renal function.

\section{DISCUSSION}

This patient experienced many common complications of typhoid fever, such as pancytopenia, delirium, hepatitis and gastrointestinal bleeding. He also developed two rare manifestations of the disease: rhabdomyolysis and renal failure. There have only been two other reported cases of rhabdomyolysis related to Salmonella typhi infection $(1,2)$. However, there have been six reported cases of rhabdomyolysis associated with Salmonella enteritidis food-borne gastroenteritis $(3,4)$.

Rhabdomyolysis is a syndrome characterized by elevated serum concentrations of CPK and myoglobinuria leading to renal dysfunction (5). This entity can be precipitated by numerous factors (5). Infections are a well known but less common cause of rhabdomyolysis, and should always be considered in the differential diagnosis. Singh and Scheld (4) recently reviewed the literature and compiled a comprehensive list of infections that have been reported to cause rhabdomyolysis (4). The spectrum of infectious agents that have been implicated is broad including viruses, bacteria, parasites and fungi. Viral infections were found to be a frequent cause of rhabdomyoly- sis, with 59 reported cases (4). Influenza is the most common viral etiology followed by HIV infection and enteroviral infection (coxsackievirus and echovirus). Other viruses reported to have caused rhabdomyolysis include Epstein-Barr virus, varicella zoster virus, cytomegalovirus and adenovirus. Bacteria were reported to cause rhabdomyolysis in 60 cases (4). Legionella species are the most common bacteria followed by Streptococcus species, Franciscella tularensis, Salmonella species, Staphylococcus aureus, Listeria species and Vibrio species. There is a case report of rhabdomyolysis from Herbicola lathyri (Enterobacter agglomerans) contamination of hyperalimentation fluid. Pseudomonal infections and leptospirosis have also been reported to cause rhabdomyolysis (4). Finally, there have been two cases of malaria, one case of candida infection and one case of aspergillus disease associated with rhabdomyolysis (4). The proposed pathophysiological mechanisms of how infections cause rhabdomyolysis include viral or bacterial invasion of skeletal muscle and toxin generation (4).

Rhabdomyolysis can be precipitated by many conditions, including infections. Physicians should be aware of the association between infections and rhabdomyolysis to aid optimal diagnosis and management of these patients.

\section{REFERENCES}

1. Rheingold OJ, Greenwald RA, Hayes PJ, Tedesco FJ. Myoglobinuria and renal failure associated with typhoid fever. JAMA 1977;238:341.

2. Barnes P, Goldstein DA, Overturf GD. Rhabdomyolysis and pancytopenia in a young man. West J Med 1986;144:586-90.

3. Sion ML, Hatzitolios A, Toulis E, Kounanis A, Prokopidis D. Rhabdomyolysis and acute renal failure associated with Salmonella enteritidis bacteremia. Nephrol Dial Transplant 1998; $13: 532$

4. Singh U, Scheld WM. Infectious etiologies of rhabdomyolysis: three case reports and review. Clin Infect Dis 1996;22:642-9.

5. Gabow PA, Kaehny WD, Kelleler SP. The spectrum of rhabdomyolysis. Medicine (Baltimore) 1982;61:141-52. 


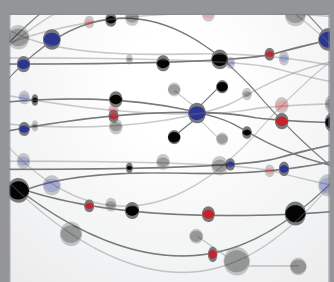

The Scientific World Journal
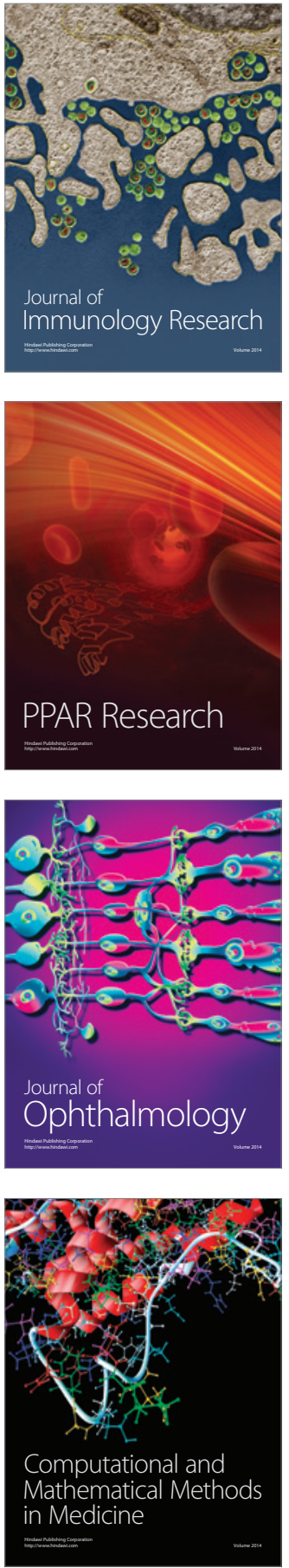

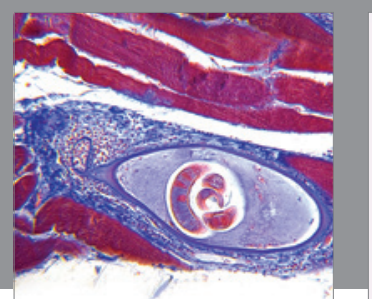

Gastroenterology Research and Practice

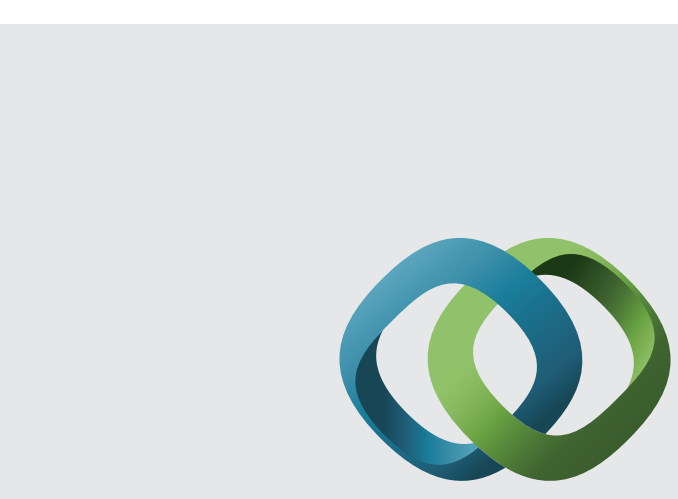

\section{Hindawi}

Submit your manuscripts at

http://www.hindawi.com
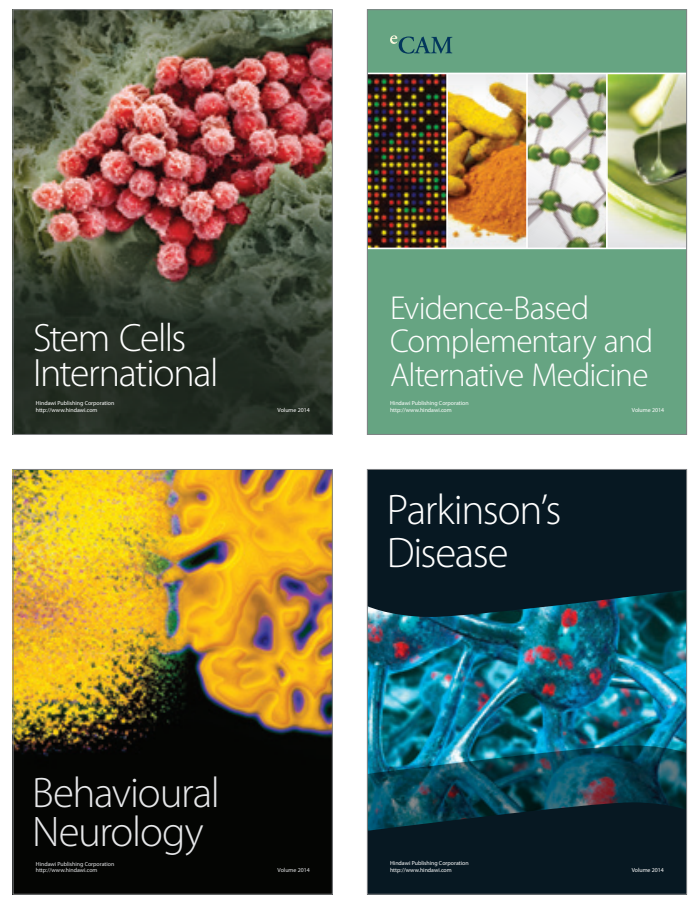
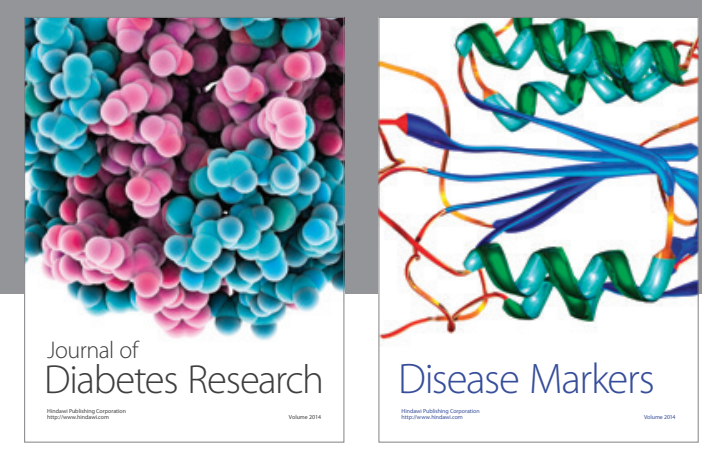

Disease Markers
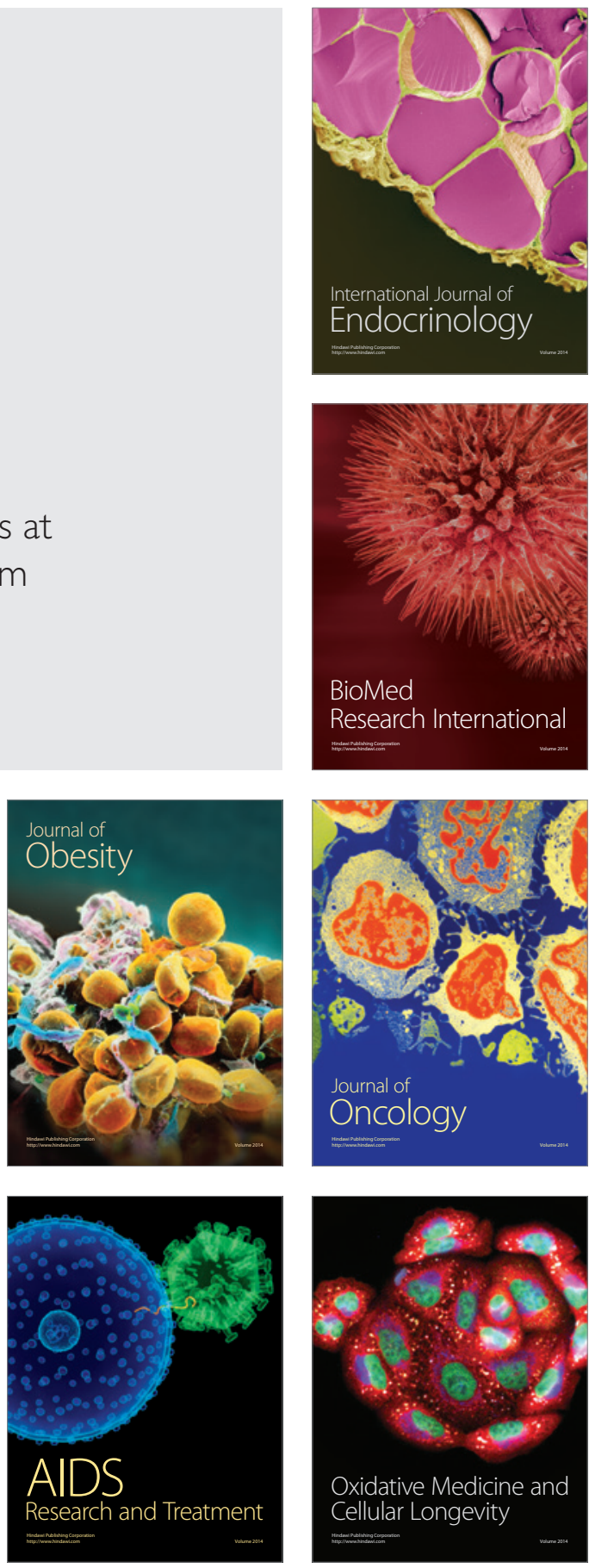